\title{
PERENCANAAN DAN PEMBUATAN ALAT PENGERING BIJI COKLAT DENGAN WADAH PUTAR MENGGUNAKAN PEMANAS LISTRIK
}

\author{
Meriadi, Selamat Meliala, Muhammad \\ Jurusan Teknik Elektro, Fakultas Teknik Universitas Malikussaleh \\ Kampus Bukit indah, Jalan Batam No. 16 Kecamatan Blangpulo Lhokseumawe \\ E-mail : selamat.meliala@unimal.ac.id
}

\begin{abstract}
Abstrak - Dalam proses pengeringan biji-bijian selama ini para petani masih menggunakan sistem manual yaitu menjemur dibawah matahari, sehingga menghabiskan waktu beberapa hari untuk mengeringkan biji-bijian tersebut. Tujuan dari pembuatan tugas akhir ini adalah membuat mesin pengering yang bisa mengeringkan biji-bijian tersebut tanpa perlu menghabiskan banyak waktu. Banyak data yang harus diperoleh dalam penyusunan tugas akhir ini yaitu menggunakan metode literature, metode tanya jawab, dan metode experimen. Hasil yang ingin dicapai adalah mesin pengering ini bisa bekerja secara optimal sehingga menghasilkan hasil pengeringan yang baik. Maka hasil dari pengujian mesin pengering biji cokelat kapasitas $1 \mathrm{~kg}$ dengan suhu maksimal pemanas listrik adalah 600, bisa mengeringkan biji cokelat tersebut dalam waktu lebih kurang 2 jam.
\end{abstract}

Keywords_- pengeringan, biji cokelat

\section{PENDAHULUAN}

Tantangan terbesar untuk meningkatkan pendapatan petani di pedesaan (terpencil) adalah pada upaya pemasaran produk-produknya. Hasil pertanian/perkebunan umumnya tidak tahan lama (cepat busuk), yang apabila tidak mendapat sentuhan penanganan pasca panen, maka waktu yang tersedia untuk pemasaran hasil sangat sempit. Karakter produk seperti ini, apalagi jika lokasi produksi jauh dari pasar, mengakibatkan posisi tawar produsen (petani) terhadap pasar menjadi sangat lemah.

Ketersediaan sarana - prasarana yang minim, mengakibatkan upaya peningkatan kualitas dan penanganan pasca panen yang dilakukan oleh petani sangat minimal dan banyak tergantung terhadap cuaca/musim. Ketergantungan terhadap cuaca/musim menghilangkan kesempatan untuk dapat memasarkan produk diluar musimnya (off season) yang berarti juga kehilangan kesempatan untuk mendapatkan harga hasil pertanian yang lebih baik di pasar. Pada saat off season supply hasil pertanian ke pasar menurun, pada saat itu harga jual hasil pertanian di pasar biasanya tinggi.

Upaya peningkatan pendapatan petani tidak cukup hanya dengan melakukan upaya-upaya peningkatan hasil pertanian saja. Peningkatan kualitas hasil pertanian dan penanganan pasca panen berperan sangat penting agar peningkatan produksi memberi manfaat yang maksimal untuk meningkatkan pendapatan petani.

Mesin Pengering Biji Cokelat Dengan Momen Wadah Putar Menggunakan Pemanas Listrik adalah alat yang dirancang untuk membantu mengeringkan biji cokelat agar proses pengeringan lebih baik dan cepat, serta pengeringan biji cokelat tidak tergantung pada musim.

\section{DASAR TEORI}

\section{Material elemen pemanas}

Material yang digunakan sebagai elemen pemanas umumnya berupa konduktor listrik yang baik, namun untuk mencapai tingkat disipasi panas yang lebih tinggi, ada kalanya konduktor listrik dicampur dengan material lain yang dapat meningkatkan kemampuan (kapasitas) panas yang dihasilkan konduktor listrik seperti lapisan isolator atau keramik yang membungkus bagian konduktor. Berdasarkan materialnya maka elemen pemanas dapat berupa:

- Elemen metalik

Elemen metalik merupakan elemen pemanas tradisional yang dibuat dari gulungan, lempengan atau lembaran logam (metal) yang bersifat konduktor dan menghasilkan panas jika dialiri listrik. Untuk masa operasi pemanasan yang lama, elemen metalik dapat mengalami degradasi disebabkan oleh proses oksidasi permukaan yang terjadi pada saat pemanasan. Oleh karena itu pemilihan jenis logam yang sesuai dengan aplikasi proses pemanasan yang akan dilakukan sangat menentukan efektifitas penggunaan elemen pemanas. Pemilihan komposisi logam yang digunakan tergantung kepada suhu operasional, resistivitas material, koefisien resistansi temperatur, koefisien resistansi perkaratan, kekuatan mekanis, kemudahan pembentukan dan biaya. Tingkat keakuratan resistivitas elemen metalik berkisar kurang lebih $5 \%$. Jenis campuran logam yang biasa digunakan sebagai elemen metalik antara lain: nikelkromium, besi-nikel-kromium dan besi-krom-alumenium. Campuran besi-krom-alumenium dapat beroperasi pada tingkat suhu lebih tinggi daripada nikel-kromium, sedangkan logam - logam khusus seperti platina, tantalum, molibdenum dan lainnya biasanya digunakan untuk keperluan khusus di 
laboratorium. Karakteristik berbagai campuran elemen metalik ini disajikan pada tabel 2.1 dibawah.

Tabel 2.1. Karakteristik dan Aplikasi berbagai material elemen metalik

\begin{tabular}{|c|c|c|c|c|}
\hline Material & $\left.\theta_{s}{ }^{\circ} \mathrm{C}\right)$ & $\rho\left(10^{-\mathrm{k} / \mathrm{m})}\right.$ & $\alpha\left(10^{-3} / \mathrm{K}\right)$ & Principal applications \\
\hline $\begin{array}{l}\text { Nickel based alloys } \dagger \\
80 \mathrm{Ni} / 20 \mathrm{Cr}\end{array}$ & 1200 & 108 & +14 & $\begin{array}{l}\text { Furnaces, resistance heaters, mineral insulated } \\
\text { elements for domestic and industrial use }\end{array}$ \\
\hline $60 \mathrm{Ni} / 15 \mathrm{Cr} / \mathrm{bal} \mathrm{Fe}$ & 1150 & 111 & +18 & $\begin{array}{l}\text { Firebar and convector heaters. Domestic and } \\
\text { furnace applications up to } 1100^{\circ} \mathrm{C}\end{array}$ \\
\hline $35 \mathrm{Ni} / 20 \mathrm{Cr} / \mathrm{bal} \mathrm{Fe}$ & 1100 & 104 & +29 & $\begin{array}{l}\text { Some domestic appliances and general heating } \\
\text { equipment at moderate temperatures }\end{array}$ \\
\hline $20 \mathrm{Ni} / 25 \mathrm{Cr} / \mathrm{bal} \mathrm{Fe}$ & 1050 & 95 & - & Terminal blocks \\
\hline $\begin{array}{l}\text { Iron based alloyst } \\
22 \mathrm{Cr} / 5.8 \mathrm{Al} / \mathrm{ball} \mathrm{Fe}\end{array}$ & 1400 & 145 & +3.2 & $\begin{array}{l}\text { Furnaces for heat treating glass, ceramics, steel, } \\
\text { electronics, ; cruciblef furnaces for melting/holding } \\
\text { aluminium and zinc }\end{array}$ \\
\hline $22 \mathrm{Cr} / 5.3 \mathrm{Al} / \mathrm{bal} \mathrm{Fe}$ & 1375 & 139 & - & Industrial furnaces \\
\hline $22 \mathrm{Cr} / 4.8 \mathrm{Al} / \mathrm{bal} \mathrm{Fe}$ & 1300 & 135 & 4.7 & Furnaces for moderate temperatures, appliances \\
\hline $\begin{array}{l}\text { Exotic metals } \\
\text { Platinum }\end{array}$ & 1300 & 10.58 & 3.92 & Laboratory furnaces, small muffe furmuces \\
\hline $90 \mathrm{Pt} / 10 \mathrm{Rh}$ & 1550 & 18.7 & - & \\
\hline $60 \mathrm{Pt} / 40 \mathrm{Rh}$ & 1800 & 17.4 & - & \\
\hline Molybdenum $\neq \leftarrow$ & 1750 & 5.7 & 4.35 & Vacuum furnaces, inert atmosphere furnaces \\
\hline Tantalum $\neq<-$ & 2500 & 13.5 & 3.5 & Vacuum furnaces \\
\hline Tungsten $\neq \Leftarrow$ & 1800 & 5.4 & 4.8 & $\begin{array}{l}\text { Incandescent lamps, vacuum and inert } \\
\text { atmosphere furnaces }\end{array}$ \\
\hline $\begin{array}{l}\text { Non-metallic materials } \\
\text { Graphiteł }\end{array}$ & 3000 & 1000 & -26.6 & Vacuum, inert gas, reducing-atmosphere furnace \\
\hline Molybdenum disilicide & 1900 & 40 & 1200 & $\begin{array}{l}\text { Glass industry, coramic kilns, metal heat } \\
\text { treatment. plus laboratory furnaces }\end{array}$ \\
\hline Silicon carbide & 1650 & $1.1 \times 40^{5}$ & - & $\begin{array}{l}\text { Furnaces for heat treatment of meals, ceramic } \\
\text { kilns, conveyor furnaces }\end{array}$ \\
\hline Lanthanum chromite & 1800 & 2100 & - & Laboratory furnaces and special ceramic kilns \\
\hline Zirconiass & 2200 & - & - & Laboratory furnaces and special ceramic kilns \\
\hline
\end{tabular}

- Elemen lembaran (sheathed elements)

Untuk melindungi bagian elemen pada berbagai kondisi lingkungan sekitar dalam berbagai aplikasi pemanasan, ada kalanya bagian logam elemen dilindungi oleh lapisan isolasi yang memisahkan elemen metalik (logam) dengan lapisan luar elemen. Elemen yang berbentuk seperti ini dinamakan elemen lembaran (sheathed elements) dan banyak digunakan pada aplikasi rumah tangga seperti peralatan memasak, pemanas celup dan elemen ketel. Elemen ini terdiri atas bubuk magnesium oksida murni yang melapisi koil elemen tembaga, nikel atau stainles steel yang berupa lembaran. Rating elemen biasanya dinyatakan dalam watt per $\mathrm{cm}^{2}$ lembaran. Selain magnesium oksida, pada aplikasi industri juga digunakan mika sebagai pelapis isolator pada elemen pemanas. Pemilihan bahan yang digunakan tergantung kepada pemakaian dengan mempertimbangkan kapasitas transfer panas, kemampuan mekanis dan elektris dan karakteristik perkaratan.

- Elemen keramik

Elemen keramik biasanya digunakan untuk aplikasi pemanasan dengan suhu yang sangat tinggi. Material yang digunakan dapat berupa silikon karbida, molibidenum disilisida, lanthanum kromite, dan zirkonia yang memiliki karkater konduktor listrik yang memungkinkan material tersebut berfungsi sebagai elemen pemanas. Selain itu dapat juga digunakan material grafite untuk aplikasi pemanasan tanpa menggunakan oksigen. Konstruksinya dapat berupa kawat spiral elemen metalik yang dilapisi lapisan keramik tebal dan kompak yang melindungi bagian metal elemen. Elemen metal yang digunakan biasanya memiliki tingkat resistansi yang rendah sehingga dapat menghasilkan panas maksimal. Karena sifat bahan keramik yang mudah pecah dan retak, maka bagian penopang elemen jenis ini harus memberi ruang gerak yang leluasa sehingga elemen keramik dapat menyesuaikan pemuaian dan penyusutan yang terjadi selama proses pemanasan tanpa menyebabkan elemen ini pecah dan retak. Karaktersitik resistivitas elemen keramik dibandingkan dengan elemen logam (metalik) diperlihatkan pada gambar 2.1 berikut:
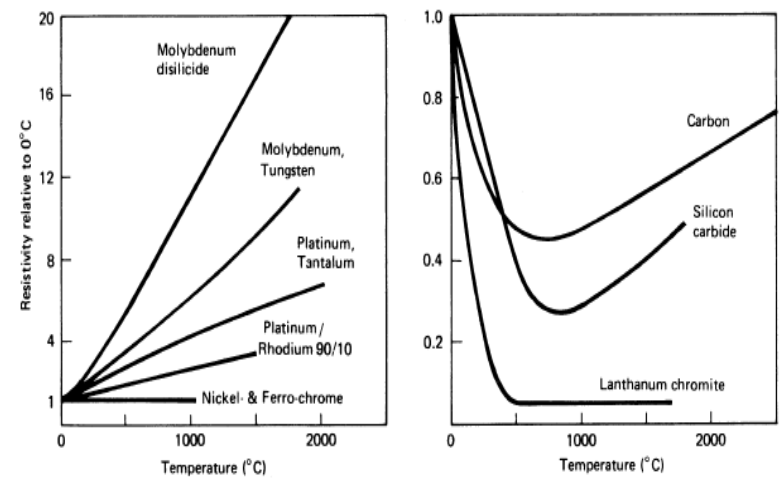

Gambar 2.1 Perbandingan karakteristik resistivitas elemen keramik dengan elemen logam

\section{Konstruksi Elemen Pemanas}

Konstruksi elemen pemanas baik yang menggunakan material logam, lembaran maupun keramik sangat tergantung kepada aplikasi pemakaian dari elemen tersebut. Hal yang perlu diperhatikan dalam konstruksi elemen pemanas adalah penggunaan material yang akan digunakan sebagai terminal atau lead dari elemen yang akan dipasang. Untuk elemen yang akan digunakan pada aplikasi dengan kondisi kelembaban tinggi, sebaiknya digunakan terminal yang tahan karat dan mampu menahan arus yang akan melalui elemen tanpa mengalami kerusakan. Lead yang akan digunakan hendaklah memiliki resistansi yang rendah dan mampu menahan besar daya pemanasan joule $\left(\mathrm{I}^{2} \mathrm{R}\right)$ yang terjadi selama pemanasan. Bentuk kontruksi yang umum digunakan pada elemen pemanas diperlihatkan pada gambar 2.2 berikut:

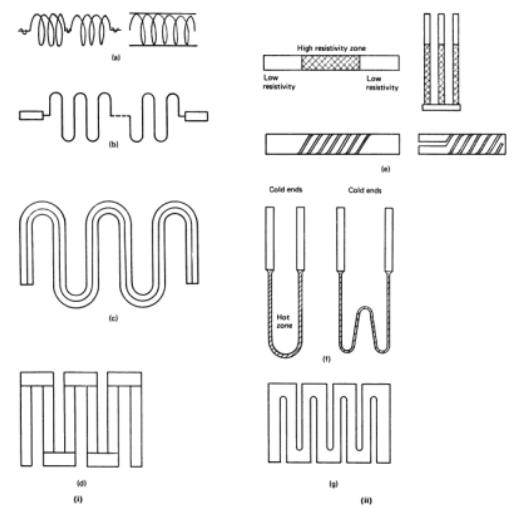

Gambar 2.2 Konstruksi elemen pemanas pada oven dan tungku pemanas: (i) elemen metalik; (a) belitan koil; (b) strip; (c) elemen plat; (d) elemen pipa; (ii) elemen pemanas non-metalik: (e) elemen silikon karbida batangan dan pipa;

(f) elemen molibdenum disilisida; (g) elemen grafit. ${ }^{[9]}$

Bila suatu logam dipanaskan maka akan terjadi pemuaian lebih tinggi akan memuai lebih panjang sedangkan yang memiliki koefisien muai lebih rendah memuai lebih pendek. 
Elemen pemanas merupakan alat pengubah tenaga listrik menjadi tenaga panas atau componen ini berfungsi sebagai penghasil panas. Pemakaian elemen pemanas sebagai sumber kalor atau panas pada alat pengering ini, prinsip kerja nya sama dengan pemanfaatan untuk keperluan alat rumah tangga seperti oven dan srtika listrik

Elemen pemanas yang digunakan harus memenuhi beberapa persyaratan sebagai berikut :

1. Tahan lama pada suhu yang dikehendaki

2. Pada suhu yang dikehendaki mekanik harus kuat

3. Koefisien muai kecil, pada suhu yang dikehendaki tidak mengalami perubahan bentuk

4. Mempunyai tahana jenis tinggi

Perpindahan panas apabila dua logam saling berhimpitan dan suhu-suhu benda itu berbeda, maka akan terjadi proses perpindahan dari benda yang panas ke benda yang lebih dingin sehingga menyebabkan suhu keduanya menjadi sama.

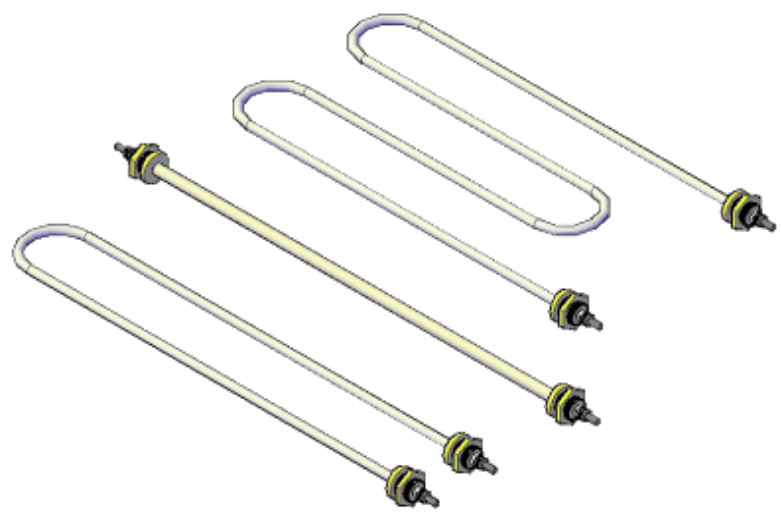

Gambar 2.3 jenis elemen yang digunakan ( tubular heater ) Berbentuk lurus , $\mathrm{U}$ form, W form multyform ataupun over the side heater.

\section{Motor DC}

Motor arus searah (motor dc) telah ada selama lebih dari seabad. Keberadaan motor dc telah membawa perubahan besar sejak dikenalkan motor induksi atau terkadang disebut ac shunt motor. Motor dc telah memunculkan kembali Silicon Controller Rectifier yang digunakan untuk memfasilitasi kontrol kecepatan pada motor.

Mesin listrik dapat berfungsi sebagai motor listrik apabila didalam motor listrik tersebut terjadi proses konversi dari energi listrik menjadi energi mekanik. Sedangkan untuk motor dc itu sendiri memerlukan suplai tegangan yang searah pada kumparan jangkar dan kumparan medan untuk diubah menjadi energi mekanik.

Pada motor dc kumparan medan disebut stator (bagian yang tidak berputar) dan kumparan jangkar disebut rotor (bagian yang berputar). Jika tejadi putaran pada kumparan jangkar dalam pada medan magnet, maka akan timbul tagangan (GGL) yang berubah-ubah arah pada setiap setengah putaran, sehingga merupakan tegangan bolak-balik. Prinsip dari arus searah adalah membalik phasa negatif dari gelombang sinusoidal menjadi gelombang yang mempunyai nilai positif dengan menggunakan komutator, dengan demikian arus yang bebalik arah dengan kumparan jangkar yang berputar dalam medan magnet, dihasilkan tegangan (GGL) seperti yang terlihat pada Gambar dibawah ini sebagai berikut :

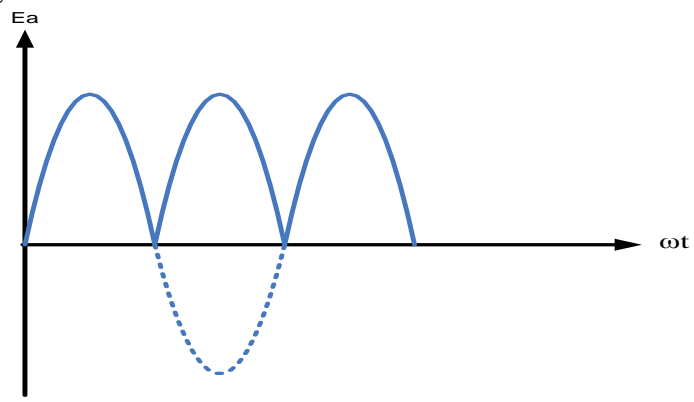

Gambar 2.4 Gelombang Arus Searah

\section{Catu Daya ( Power Suplay )}

Perangkat elektronika mestinya dicatu oleh suplai arus searah DC (direct current) yang stabil agar dapat dengan baik. Baterai atau accu adalah sumber catu daya DC yang paling baik. Namun untuk aplikasi yang membutuhkan catu daya lebih besar, sumber dari baterai tidak cukup. Sumber catu daya yang besar adalah sumber bolak-balik AC (alternating current) dari pembangkit tenaga listrik. Untuk itu diperlukan suatu perangkat catu daya yang dapat mengubah arus AC menjadi DC. Pada tulisan kali ini disajikan prinsip rangkaian catu daya (power supply) linier mulai dari rangkaian penyearah yang paling sederhana sampai pada catu daya yang ter-regulasi.

Prinsip penyearah (rectifier) yang paling sederhana ditunjukkan pada gambar 2.10 sebagai berikut. Transformator diperlukan untuk menurunkan tegangan AC dari jala-jala listrik pada kumparan primernya menjadi tegangan AC yang lebih kecil pada kumparan sekundernya.

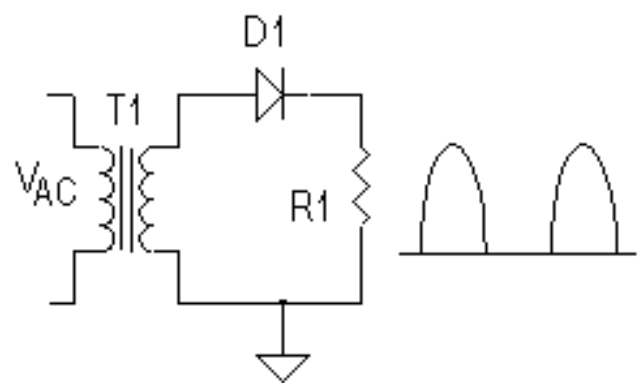

Gambar 2.5 Rangkaian penyearah sederhana

III. METODOLOGI

\section{Langkah langkah pembuatan}


Sebelum membuat modul Mesin Pengering Biji Coklat Dengan Momen Wadah Putar Menggunakan Elemen Pemanas Listrik, kita harus menentukan langkah-langkah pembuatan alat tersebut, berikut susunan langkah-langkah pembuatannya:

1. menentukan alat yang di pakai

2. menentukan standart (spesifikasi) alat yang di pakai sesuai dengan aslinya

3. melakukan penempatan atau pemasangan alat yang akan di uji

4. membuat instalasi rangkaian ( wireing)

5. melakukan pengujian mesin pengering biji coklat dengan momen wadah putar menggunakan elemen pemanas listrik

\section{Kontruksi Pembuatan Rangka Mesin Pengering Biji Cokelat}

Langkah pertama yang penulis lakukan dalam pembuatan mesin pengering ini adalah membuat rangka. Mesin pengering hasil pertanian ini berbentuk seperti piramid dengan tinggi $100 \mathrm{~cm}$ dan lebar $60 \mathrm{~cm}$. Rangkanya terbuat dari besi siku dan memiliki 4 rak untuk meletakkan bijibijian yang akan dikeringkan.

Operasi dari rangkaian mesin pengering biji cokelat ini tergantung pada suhu yang mendisipasikan panas yang ditimbulkan oleh arus yang melewati elemen pemanas. Sehingga pada rating arus yang besar, panas yang ditimbulkan bisa mencapai harga yang tinggi. Rangkaian ini menggunakan tegangan 220 Volt, catu daya yang distabilkan sebesar 12 VDC dan tegangan kerja untuk trafo sebesar 220 V. Setelah menentukan semuanya maka penulis akan memulainya dengan merakit rangkaian mesin pengering. Beberapa komponen yang digunakan yaitu :

Komponen

1. catu daya

1 buah

2. saklar tunggal

1 buah

3. fuse $\mathrm{AC} 2 \mathrm{~A}$

1 buah

4. fuse DC $20 \mathrm{~A}$

2 buah

5. Saklar DC 3 arah

1 buah

6. Kipas DC $12 \mathrm{~V}$

5 buah

7. Heat selector

1 buah

8. Timer bell $10-60$ menit

1 buah

9. Temperatur control $100^{\circ} \mathrm{C}-250^{\circ} \mathrm{C}$

1 buah

10. Elemen pemanas jenis tubular heater 350 watt

11. Motor DC $12 \mathrm{~V}$

2 buah

12. Stop kontak

1 buah

13. Lampu indicator

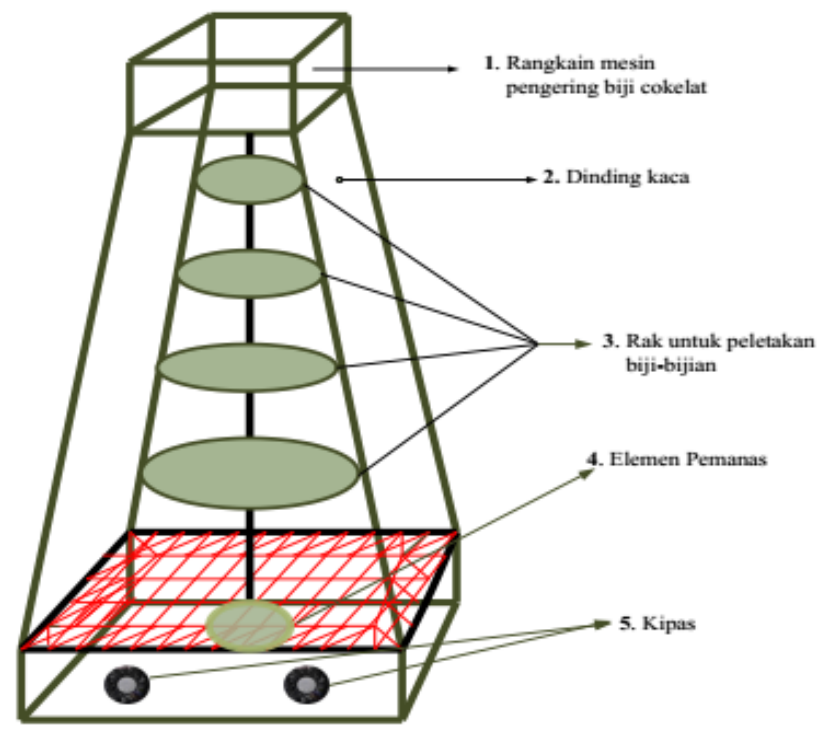

Gambar 3.1 Modul Mesin Pengering Biji Cokelat

\section{Elemen Pemenas Untuk Mengeringkan Biji Cokelat}

Elemen pemanas adalah komponen utama yang digunakan dalam modul ini yaitu sebagai pemanas untuk mengeringkan biji cokelat yang ada pada wadah pengering. Bahan-bahan yang digunakan untuk membuat elemen pemanas ini adalah :

1. Korm-nikel

2. Korm-nikel-besi

3. Korm-nikel-aluminium

Demi tercapainya suatu keselamatan dan mengurangi terjadinya kerugian dan kecelakaan akibat listrik maka kawat dari elemen pemanas harus memenuhi syarat sebagai berikut:

1. Harus tahan lama pada suhu operasi yang dikehendaki

2. Konstruksi mekanisnya harus cukup kuat dan tidak rapuh pada suhu yang dikehendaki

3. Koefesien muainya harus kecil mungkin sehingga tidak mempengaruhi bentuknya saat berada suhu yang dikehendaki

4. Koefesien suhu juga harus sekecil mungkin sehingga arus kerja sedapat mungkin konstan.

Bahan-bahan yang digunakan sebagian besar ditentukan oleh suhu maksimum yang dikehendaki. Logam-logam di atas dapat pada suhu $100^{\circ} \mathrm{C}$ hingga $1250^{\circ} \mathrm{C}$. Sebagai bahan pelindung panas diperlukan isolasi anti panas yang tidak boleh mengadakan reaksi kimia dengan bahan kawat terutama pada saat mencapai suhu penggunaanya. Syarat ini penting sekali diperhatikan, terutama untuk bahan isolasi dari keramik. Adapun bahan isolasi keramik yang digunakan antara lain adalah porselen.

Untuk Elemen pemanas merupakan alat pengubah tenaga listrik menjadi tenaga panas atau komponen ini berfungsi sebagai penghasil panas. Pemakaian elemen pemanas sebagai sumber kalor atau panas pada alat pengering ini, 
prinsip kerja nya sama dengan pemanfaatan untuk keperluan alat rumah tangga seperti oven dan srtika listrik

Elemen pemanas yang digunakan harus memenuhi beberapa persyaratan sebagai berikut :

1. Tahan lama pada suhu yang dikehendaki

2. Pada suhu yang dikehendaki mekanik harus kuat

3. Koefisien muai kecil, pada suhu yang dikehendaki tidak mengalami perubahan bentuk

4. Mempunyai tahana jenis tinggi

Perpindahan panas apabila dua logam saling berhimpitan dan suhu-suhu benda itu berbeda, maka akan terjadi proses perpindahan dari benda yang panas ke benda yang lebih dingin sehingga menyebabkan suhu keduanya menjadi sama. Sistem ini menggunakan elemen pemanas dalam ruang mesin pengering biji coklat yang menyebabkan udara dalam ruang terinduksi panas. Kemudian udara panas disirkulasikan oleh kipas-kipas dan diarahkan dengan menggunakan plafon antara (sub-celling). Bila udara panas ini sudah jenuh dengan uap air yang dievaporasi dari biji coklat, maka udara itu akan dibuang melalui celah pembuangan dan pada saat yang sama di masukkan udara bersih ke dalam ruang.

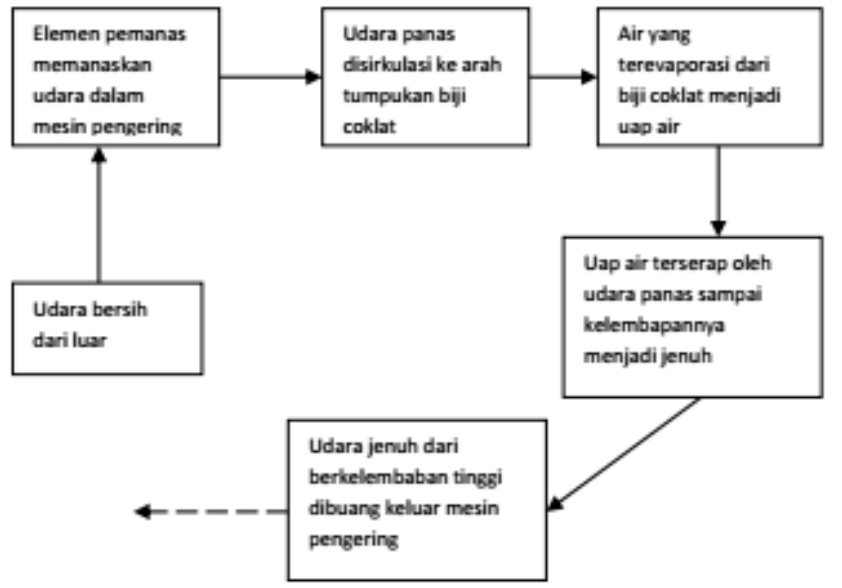

Gambar 3.2 Skema prinsip kerja mesin pengering biji coklat

\section{Rangkaian Catu Daya Untuk Penyearah Rangkaian Kontrol}

Catu daya merupakan rangkaian elektronika yang dapat mengubah sumber tegangan AC (alternating current) menjadi tegangan DC (diretional current), dan berfungsi memberi supply arus dan tegangan pada suatu rangkaian elektronika atau peralatan yang menggunakan listrik lainnya. Prinsip dasar untuk memperoleh tegangan searah DC dari tegangan jala-jala (AC) Dari tegangan jala-jala, masukan tegangan bolak-balik (AC) diturunkan sesuai dengan besar tegangan yang diinginkan. Tegangan dari jala-jala diturunkan oleh transformator, yang kemudian disearahkanoleh rangkaian penyearah. Hasil penyearahaan diratakan oleh filter atau penyaring dan akhirnya distabilkan oleh rangkaian pengatur tegangan atau regulator untuk mendapatkan keluaran tegangan searah(DC) yang konstan.
Penyearah gelombang penuh, seperti yang nampak dalam gambar 3.2 dibawah ini

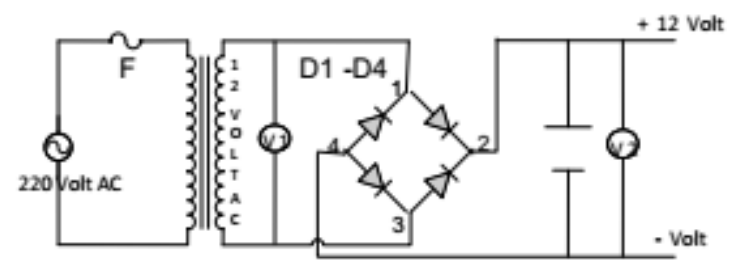

Gambar 3.3 Rangkaian Catu Daya mesin pengering biji coklat

Keluaran dari ujung atas gulungan skunder adalah positif terhadap ujung bawahnya, arus akan melewati D2 dan mengisi muatan kondensator $\mathrm{C} 1$, begitu pula ujung bawah gulungan adalah positif arus akan mengalir lewat D4 dan mengisi C1 lalu kembali melewati D1.

Karena tegangan keluaran adalah 1,414 kali tegangan efektif yang ada di skunder transfomator dalam kondisi tanpa beban. Dalam rangkaian penyearah jembatan ini untuk mendapatkan tegangan DC yang murni maka digunakan 4 buah dioda yang dipasang secara sistem jembatan atau brigdge dan setelah itu dipasangkan elco secara paralel yang bertujuan untuk mengecilkan ripple ataupun tegangan kerut pada jalur catu daya yang terlihat pada gambar 3.2 diatas. Beberapa sistem yang di bangun membutuhkan catu daya. Dalam perancangan ini dibutuhkan catu daya sebesar 12 volt. AC input adalah keluaran dari llitan sekunder trafo. Tegangan yang digunakan adalah 12 volt DC, dengan pemasangan dioda akan menghasilkan penyearah gelombang penuh. Pemasangan buah kapasitor 2200uf/25v bertujuan untuk meratakan arus dan menghilangkan riple, pemberian kapasitor juga bertujuan agar tidak terjadi drop tegangan saat catu daya diberii beban.

\subsection{Rangkaian Mesin Pengering biji coklat}

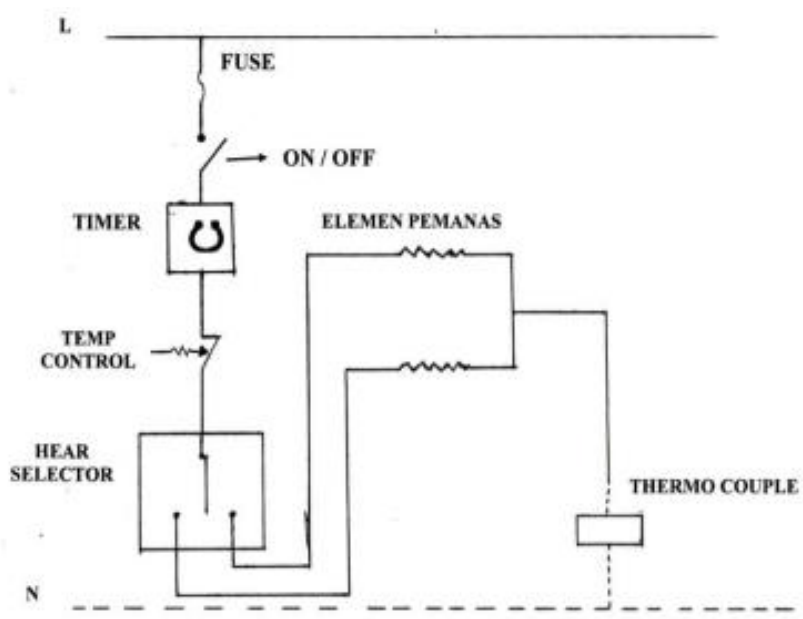

Gambar 3.4 Rangkaian kontrol elemen pemanas

Rangakaian kontrol elemen pemanas ini mengunakan beberapa alat kontrol yaitu timer, heat selector dan temperatur control, elemen pemanas yang digunakan adalah jenis Tubular heater, dimana dalam rangkaian ini digunakan 
2 buah elemen pemanas, dengan masing masing elemen pemanas berdaya 350 watt, 220 volt AC.

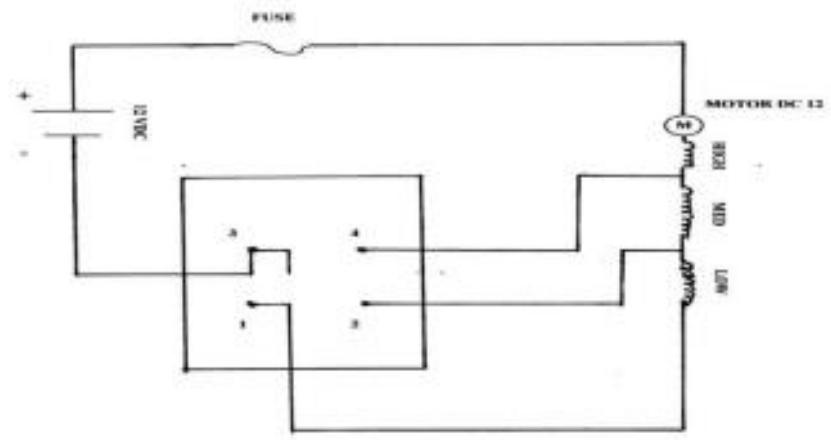

Gambar 3.5 Rangkaian kontrol wadah putar

Rangkaian kontrol wada putar ini mengunakan arus DC 12 volt, dimana arus ini didapat dari catu daya atau power suplai. Wadah putar digerakan oleh motor DC 12 volt dan diatur kecepatanya oleh resistor, ini dimungkinkan dapat mengatur dengan 3 pilihan kecepatan, high, medium dan low.

\section{PENGUJIAN DAN PEMBAHASAN}

\section{Hasil Pengujian}

Penulis melakukan analisa pengujian untuk melakukan koreksi-koreksi agar mendapatkan hasil yang lebih baik, dalam pengujian dan analisa ini penulis melakukan pengujian pada elemen pemanas. Pengujian yang penulis lakukan yaitu berapa suhu maksimal dari elemen pemanas yang penulis gunakan pada mesin pengering bjii cokelat ini dan dalam waktu berapa menit elemen tersebut mencapai suhu maksimalnya. Dengan skema pengujian

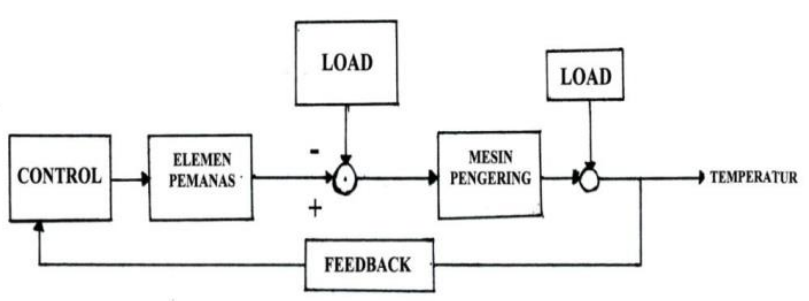

Gambar 4.1 blok diagram pengujian

Tabel Pengamatan Hasil Pengukuran Waktu Dan Suhu

Suhu awal elemen pemanas pada saat dihidupkan adalah $31^{0}$. Berikut dibawah ini tabel pengukuran elemen pemanas.
Tabel 4.2.1 Hasil pengukuran tanpa biji cokelat

\begin{tabular}{|c|c|}
\hline Waktu (menit) & Suhu C \\
\hline 5 & $37^{0}$ \\
\hline 10 & $41^{0}$ \\
\hline 15 & $43^{0}$ \\
\hline 20 & $45^{0}$ \\
\hline 25 & $47^{0}$ \\
\hline 30 & $48^{0}$ \\
\hline 35 & $49^{0}$ \\
\hline 40 & $49^{0}$ \\
\hline 45 & $50^{0}$ \\
\hline 50 & $50^{0}$ \\
\hline 55 & $51^{0}$ \\
\hline 60 & $55^{0}$ \\
\hline
\end{tabular}

Tabel 4.2.2 Hasil pengukuran waktu dan suhu pengujian 1 $\mathrm{kg}$ biji cokelat

\begin{tabular}{|c|c|c|}
\hline $\begin{array}{l}\text { Waktu } \\
\text { (menit) }\end{array}$ & Suhu $\mathrm{C}^{0}$ & $\begin{array}{c}\text { Keadaan Biji } \\
\text { Cokelat }\end{array}$ \\
\hline 5 & $33^{0}$ & Basah \\
\hline 10 & $38^{0}$ & Basah \\
\hline 15 & $41^{0}$ & Basah \\
\hline 20 & $44^{0}$ & Lembab \\
\hline 25 & $47^{0}$ & Lembab \\
\hline 30 & $47^{0}$ & Lembab \\
\hline 35 & $48^{0}$ & Lembab \\
\hline 40 & $49^{0}$ & Lembab \\
\hline 45 & $49^{0}$ & Lembab \\
\hline 50 & $50^{0}$ & Mulai Kering \\
\hline 55 & $50^{0}$ & Mulai Kering \\
\hline 60 & $55^{0}$ & Mulai Kering \\
\hline 120 & $60^{0}$ & Kering \\
\hline
\end{tabular}

\section{Pengujian Lama Waktu Pengeringan}

Pada pengujian mesin pengering biji coklat secara keseluruhan ini dilakukan dengan mengukur lama waktu proses pengeringan. Yang mana lama waktu ini tidak hanya ditentukan oleh berapa derajat panas suhu yang dipakai tetapi juga oleh kadar air yang terkandung didalam bahan yang akan dikeringkan, untuk mengukur jumlah kadar air pada bahan ini, penulis menggunakan metode gravimetri untuk mengukur kadar air pada kedua bahan yang akan diuji. Disini penulis dalam melakukan pengujian menggunakan bahan yang akan dikeringkan yaitu biji coklat. Dimana bahan tersebut mempunyai kadar air. Pengujian dengan menggunakan 1000 gram bji coklat sebagai sampel, yang mempunyai berat basah awal 1000 gram dengan kadar air basis basah sekitar $38 \%$, perhitungan kadar air basis basah dan kadar air basis kering didapat dengan menggunakan persamaan 1 dan 2, yaitu bobot air (Ba) pada bahan dinyatakan dengan bobot bahan sebelum pengeringan dikurangi bobot bahan setelah pengeringan. Maka, bobot bahan awal atau sebelum dikeringkan sebesar $1 \mathrm{~kg}$ dikurangi 
dengan basis bahan setelah pengeringan yaitu 720 gram hasilnya didapat 280 gram $(\mathrm{Ba})$, dan bobot bahan kering mutlak (berat akhir) didapat dari bobot bahan setelah pengeringan yaitu 720 gram (Bk).

Maka,

$$
\begin{gathered}
\text { Kadar air basis basah (\%) }=\frac{B a}{B k} \times 100 \% \\
\text { Kadar air basis basah }(\%)=\frac{280}{720} \times 100=38 \%
\end{gathered}
$$

Kadar air basis kering (\%)

$$
=\frac{\text { Berat awal }- \text { Berat akhir }}{\text { Berat awal }} \times 100 \%
$$

$$
\begin{gathered}
\text { Kadar air basis } \text { kering }(\%)=\frac{1000-720}{1000} \times 100 \% \\
=25 \%
\end{gathered}
$$

Setelah diketahui basis basah dan basis kering dari bahan tersebut, dapat diketahui lama waktu proses pengering akan berlangsung, dengan kadar air saat basis basah sebesar $38 \%$ dan saat basis kering sebesar $25 \%$.

\section{Analisa}

Pada saat para petani melakukan pengeringan atau penjemuran biji cokelat, mereka menjemur biji cokelat dibawah sinar matahari dengan suhu $35^{\circ}$. Apabila sinar matahari pada saat penjemuran biji cokelat tersebut cerah, biji cokelat tersebut bisa kering dalam waktu 2 atau 3 hari. Suhu awal pada saat penulis melakukan pengeringan biji cokelat adalah $31^{\circ}$. Suhu maksimal dari pemanas listrik adalah $60^{\circ}$, suhu tersebut diperoleh setelah mesin pengering bekerja 1 satu jam. Setelah penulis melakukan pengujian mengeringkan biji cokelat menggunakan mesin pengering biji cokelat dengan wadah putar menggunakan pemanas listrik dengan suhu maksimal $60^{\circ}$, biji cokelat tersebut bisa dikeringkan dalam waktu lebih kurang 2 jam. Dari hasil pengujian yang penulis lakukan maka dapat diambil kesimpulan bahwa mesin pengering biji cokelat lebih efisien dari pada pengeringan manual yaitu menjemur dibawah matahari dan tidak memerlukan waktu yang lama untuk mengeringkan biji cokelat.

\section{KESIMPULAN}

Adapun hasil yang dicapai dari pengujian dapat diambil beberapa kesimpulan sebagai berikut:

1. Proses pengeringan biji cokelat kapasitas $1 \mathrm{~kg}$ menggunakan pemanas listrik menghasilkan hasil yang memuaskan.

2. Suhu awal dari pemanas listrik pada saat diberi sumber untuk mengeringkan biji cokelat adalah $30^{\circ}$. Suhu maksimal dari pemanas listrik yang penulis gunakan adalah $60^{\circ}$, suhu tersebut dihasilkan setalah mesin pengering bekerja 60 menit dan membutuhkan waktu lebih kurang 120-160 menit untuk proses pengeringan biji cokelat tersebut dengan suhu maksimal dari pemanas listrik adalah $60^{\circ}$.

3. Lama waktu untuk mengeringkan bahan tergantung dari suhu yang dipakai dan kandungan air dari bahan yang dikeringkan, untuk biji coklat dengan kadar air sekitar $23 \%$ dikeringkan dengan suhu sekitar $60^{\circ} \mathrm{C}$ di butuhkan waktu 120 menit -160 menit.

4. disini nampak bahwa untuk mengeringkan biji coklat waktu yang dibutuhkan alat pengering ialah 120 menit - 160 menit. Sedang untuk pengeringan dengan bantuan sinar matahari waktunya lebih lama sekitar 800 - 1100 menit.

5. Untuk energi yang dibutuhkan dalam perhitungan nampak bahwa semakin lama proses pengeringan semakin besar energi yang dibutuhkan untuk melakukan proses pengeringan. Arus yang mengalir pada pemanas konstan atau tetap karena beban tetap dan tidak berubah-ubah.

\section{REFERENSI}

[1] Asprianto N, 1999, sistem kontrol suhu untuk proses pengeringan, Edisi Ketujuh. Jakarta; Binacipta.

[2] Daryanto, 2000, Teknik Pengerjaan Listrik, Penerbit Bumi Aksara, Jakarta.

[3] http;//www.Google.co.id/2007/09/12/penyearah (Diakses tanggal 23 April 2014)

[4] Malvino, Albert Paul. 2003. Prinsip-Prinsip Elektronika. Edisi Pertama. Jakarta; Salemba Teknika.

[5] Mujumdar dan Devahastin, 2002, Jurnal MekanismePengeringan Terhadap Perbedaan Konsentrasi Pada Bagian Dalam Dan Bagian Luar Bahan, Jakarta.

[6] Rijono Y, 2002, Dasar Teknik Tenaga Listrik, Eidisi Revisi, Andi Yogyakarta.

[7] Zuhal. 1993. Dasar Teknik Tenaga Listrik Dan Elektronika Daya. Jakarta; Gramedia Pustaka Utama. 